MSC 35R30, 35Q35, 65M60, 65M32

DOI: $10.14529 / \mathrm{mmp} 190107$

\title{
ON SOME INVERSE COEFFICIENT PROBLEMS WITH THE POINTWISE OVERDETERMINATION FOR MATHEMATICAL MODELS OF FILTRATION
}

\author{
S.N. Shergin ${ }^{1}$, E.I. Safonov ${ }^{1}$, S.G. Pyatkov ${ }^{1,2}$ \\ ${ }^{1}$ Ugra State University, Khanty-Mansyisk, Russian Federation \\ ${ }^{2}$ South Ural State University, Chelyabinsk, Russian Federation \\ E-mails: S_pyatkov@ugrasu.ru, Ssn@ugrasu.ru,dc.gerz.hd@gmail.com
}

\begin{abstract}
We examine inverse problems of recovering coefficients in a linear pseudoparabolic equation arising in the filtration theory. Boundary conditions of the Neumann type are supplemented with the overtermination conditions which are the values of the solution at some interior points of a domain. We expose existence and uniqueness theorems in the Sobolev spaces. The solution is regular, i. e., it possesses all generalized derivatives occurring in the equation containing in some Lebesgue space. The method of the proof is constructive. The problem is reduced to a nonlinear operator equation with a contraction operator whenever the time interval is sufficiently small. Involving the method of the proof, we construct a numerical algorithm, the corresponding software bundle, and describe the results of numerical experiments in the two-dimensional case in the space variables. The unknowns are a solution to the equation and the piezo-conductivity coefficient of a fissured rock. The main method of numerical solving the problem is the finite element method together with a difference scheme for solving of the corresponding system of ordinary differential equations. Finally, the problem is reduced to a system of nonlinear algebraic equations which solution is found by the iteration procedure. The results show a good convergence of the algorithms.
\end{abstract}

Keywords: inverse problem; pseudoparabolic equation; filtration; fissured rock; numerical solution.

\section{Introduction}

In 1960, G.I. Barenblatt, Iu.P. Zheltov and I.N. Kochina (see [1]) proposed the basic concept in the theory of seepage (filtration) of homogeneous liquids in fissured rocks. A fissured rock is considered as a material consisting of pores and permeable blocks which are generally separated from each other by a system of fissures. In contrast to to the conventional arguments of filtration in a porous medium, the significant feature lies in the fact that two liquid pressures, both in the pores and in the fissures, are introduced at any point in a space and the transfer of liquids between the fissures and the pores is taken into consideration. The corresponding model is written as

$$
\nu \Delta u_{1}+\alpha\left(u_{2}-u_{1}\right)=0, \quad \mu\left(m_{0} d_{1}+d_{2}\right) u_{2 t}+\alpha\left(u_{2}-u_{1}\right)=0,
$$

where $u_{1}(t, x), u_{2}(t, x)$ are the pressures of the liquid in the fissures and pores, respectively; $\Delta$ is the Laplacian, $d_{1}$ and $d_{2}$ are the coefficients of compressibility of the liquid and the blocks, $m_{0}$ stands for the magnitude of the porosity of the blocks at standard pressure; $\mu$ is the viscosity of the liquid, and $\nu$ represents the permeability of fissures. The dimensionless coefficient $\alpha$ characterizes the intensity of the liquid transfer between the blocks and fissures. More general models can include the nonlinearities arising from fluid type (liquid or gas), concentration (porosity, absorption or saturation) and the exchange rate [2]. 
Eliminating $u_{2}$ from (1) we obtain for the pressure of the liquid in the fissures the so-called fissured medium equation of pseudoparabolic type

$$
u_{1 t}-\eta \Delta u_{1 t}-k \Delta u_{1}=0, \quad k=\nu /\left(m_{0} d_{1}+d_{2}\right), \eta=\nu / \alpha
$$

The parameter $k$ corresponds to the piezo-conductivity of fissured rock. The pressure of the liquid in the pores $u_{2}$ satisfies a similar equation. Since the natural stratum is involved, the parameters of fissured rock in (2) should be determined on the basis of the investigation of their behavior under the natural nonsteady-state conditions. This leads to the interest in studying the inverse problems for equation (2) and its analogues. More general equations can be written in form

$$
L(t, x, D) u_{t}-M(t, x, D) u=f,(x, t) \in Q=G \times(0, T)
$$

where $L, M$ are second order operators and $G$ is a bounded domain in $\mathbb{R}^{n}$. The equation (3) is furnished with initial and boundary conditions of form

$$
u(0, x)=u_{0}(x),\left.\quad R u\right|_{S}=g(t, x)
$$

with $R u=u$ or $R u=\sum_{i=1}^{n} \gamma_{i}(t, x) u_{x_{i}}+\sigma(t, x) u$ (other boundary conditions are also possible). Pseudoparabolic equations of form (3) with various differential operators $L_{1}$ and $L_{2}$ of the even order in spacial variables also arise in the mathematical models of the heat conduction, wave processes quasistationary processes in semiconductors and magnetics, in the models for filtration of the two-phase flow in porous media with the dynamic capillary pressure (see [3, 4, Sect. 0.1.4] and the bibliography therein). Detailed bibliography and the results concerning the solvability of direct problems for pseudoparabolic equations can be found, for instance, in $[5,6]$. The first results devoted to inverse problems for pseudoparabolic equations were obtained in [7], where an inverse problems of recovering an unknown source $f$ of a special form in (3) is considered. Large number of results is exposed in the monographs [8-10]. We mention also the article [11] devoted to some coefficients inverse problems with lower order coefficients depending on spatial variables being the unknowns. The problems of recovering coefficients, in particular, the coefficients $k(t)$ and $\eta$ are studied in $[12,13]$, where integral overdetermination conditions are used. Closed results with pointwise overdetermination conditions are presented in [14]. Exposition of numerical methods for solving inverse problem can be found, for instance, in $[15,16]$. We can refer also to articles [17-24] devoted to different numerical methods of solving boundary value problems for pseudo-parabolic equations. At the same time, the number of articles devoted to a numerical solution of inverse problems for pseudo-parabolic equations is rather limited (see, for instance, $[24,25])$. Most of the articles are devoted to different model problems. In the present article we generalize the results in [14] to the case of the oblique derivative problem, describe numerical methods applicable to a wide class of inverse problems with pointwise ovedetermination, and present the results of numerical experiments in the case of recovering the piezo-conductivity coefficient of fissured rock in equation (2). 


\section{Preliminaries}

We consider a general inverse problem on recovering functions occurring into the righthand side and left-hand side of the equation. Let the right-hand in (3) be of form

$$
f=\sum_{i=1}^{r_{0}} c_{i}(t) f_{i}(x, t)+f_{0}(x, t), \quad f_{i} \in L_{\infty}\left(0, T ; L_{p}(G)\right),
$$

where functions $f_{i}$ are given. We assume that

$$
L=\sum_{i, j=1}^{n} a_{i j}(t, x) \partial_{x_{i} x_{j}}+\sum_{i=1}^{n} a_{i}(t, x) \partial_{x_{i}}+a_{0}(t, x)
$$

and operator $M$ is representable as

$$
\begin{gathered}
M u=M_{r_{0}} u+\sum_{k=r_{0}+1}^{r} c_{k}(t) M_{k} u \\
M_{k} u=\sum_{i, j=1}^{n} b_{i j}^{k}(x, t) u_{x_{i} x_{j}}+\sum_{i=1}^{n} b_{i}^{k}(x, t) u_{x_{i}}+b_{0}^{k}(x, t) u,
\end{gathered}
$$

where functions $c_{i}(t)$ are unknown. Our problem is stated as follows: find functions $\left\{c_{i}(t)\right\}_{i=1}^{r}$ and solution $u$ to the problem (3) - (4) such that

$$
u\left(x_{i}, t\right)=\alpha_{i}(t), \quad(i=1,2, . ., r),
$$

where $x_{i}$ are arbitrary points lying in $G$ and $\alpha_{i}(t)$ are given functions. Put $(u, v)=$ $\int_{G} u(x) \overline{v(x)} d x$.

We employ the Sobolev spaces $W_{p}^{s}(G)$ and Hölder spaces $C^{\alpha}(\bar{G})$ (see the definitions in [26]). Symbol $L_{p}(0, T ; H)$ ( $H$ is a Banach space) stands for the space of strongly measurable functions defined on $[0, T]$ with values in $H$. Given an interval $J=(0, T)$ and domain $G \in \mathbb{R}^{n}$, put $Q=(0, T) \times G$ and $W_{p}^{r, s}(Q)=W_{p}^{r}\left(J ; L_{p}(G)\right) \cap L_{p}\left(J ; W_{p}^{s}(G)\right)$. Respectively, $W_{p}^{s, r}(S)=W_{p}^{r}\left(J ; L_{p}(\Gamma)\right) \cap L_{p}\left(J ; W_{p}^{s}(\Gamma)\right)(S=(0, T) \times \partial G)$. Similarly, we can define the Hölder spaces $C^{r, s}(\bar{Q})$.

Next, we describe the condition on the data of the problem. We assume that operator $L$ is elliptic, i. e., there exists constant $\delta>0$ such that

$$
\sum_{i, j=1}^{m} a_{i j} \xi_{i} \xi_{j} \geq \delta_{0}|\xi|^{2}, \quad \forall \xi \in R^{n}, \quad \forall(x, t) \in \bar{Q} .
$$

Fix parameter $p>n$ and assume that

$$
\begin{aligned}
& b_{i j}^{k} \in L_{\infty}(Q), b_{i}^{k}, b_{0}^{k} \in L_{\infty}\left(0, T ; L_{p}(G)\right) \quad\left(k=r_{0}, \ldots, r\right), \\
& a_{i j} \in C(\bar{Q}), \quad a_{i}, a_{0} \in C\left([0, T] ; L_{p}(G)\right)(i, j=1,2, . ., n) .
\end{aligned}
$$

We also suppose that

$$
a_{0}(x, t) \leq 0 \text { a.e. (almost everywhere) in } Q
$$

in the case of the Dirichlet boundary conditions

and $a_{0}^{0} \leq 0$ a.e. in $Q$ and $a_{0}^{0}<0$ a.e. in some neighborhood about $S$ in the case of the oblique derivative problem. 
We also assume that

$$
\begin{gathered}
\gamma_{i}, \gamma_{i t}, \sigma, \sigma_{t} \in C^{1 / 2,1}(\bar{S}), i=1,2, \ldots, n \\
\alpha_{i}(0)=u_{0}\left(x_{i}, t\right) \quad(i=1,2, . ., r),\left.B(0, x, D) u_{0}\right|_{\Gamma}=g(0, x) .
\end{gathered}
$$

Let $s_{0}=2-1 / p$ in the case of the Dirichlet boundary condtions and $s_{0}=1-1 / p$ otherwise. We can determine function $\Phi \in C\left([0, T] ; W_{p}^{2}(G)\right)(p>n)$ such that $\Phi_{t} \in$ $L_{p}\left(0, T ; W_{p}^{2}(G)\right),\left.\Phi\right|_{t=0}=u_{0}(x)$, and $\left.R \Phi\right|_{S}=g$. Construct matrix $B$ with the rows

$$
L^{-1} f_{1}\left(x_{j}, t\right), . ., L^{-1} f_{r_{0}}\left(x_{j}, t\right),-L^{-1} M_{r_{0}+1} \Phi\left(x_{j}, t\right), . .,-L^{-1} M_{r} \Phi\left(x_{j}, t\right),
$$

where $j=1,2, \ldots, r$ and assume that the there exists constant $\delta_{0}>0$ such that

$$
|\operatorname{det} B| \geq \delta_{0} \quad \forall t \in[0, T]
$$

Here $L^{-1} f_{i}$ is solution $U_{i}$ to problem $L U_{i}=f_{i},\left.U_{i}\right|_{t=0}=0,\left.R U_{0}\right|_{S}=0$. In this case, it is easy to justify that locally in time conditions (12) does not depend on the choice of function $\Phi$.

The following theorem is proven in [14] for the case of the Dirichlet boundary conditions. Here we expose the claim in the general case.

Theorem 1. Let the conditions (7) - (12), (A) be fulfilled. Then there exists a constant $\gamma_{0}>0$ such that on interval $\left[0, \gamma_{0}\right]$ problem $(3)-(6)$ has unique solution $\left(u, c_{1}, \ldots, c_{r}\right)$ such that

$$
u \in W_{p}^{1}\left(0, \gamma_{0} ; W_{p}^{2}(G)\right), \quad c_{i}(t) \in L_{p}\left(0, \gamma_{0}\right)(i=1,2, \ldots, r) .
$$

Proof. In the case of the oblique derivative problem the proof almost repeats that in the case of the Dirichlet boundary conditions. So we present the proof omitting some details. Let function $\Phi \in C\left([0, T] ; W_{p}^{2}(G)\right)$ such that $\Phi_{t} \in L_{p}\left([0, T] ; W_{p}^{2}(G)\right)$ be a solution to the direct problem (see the existence theorem in [14])

$$
L \Phi_{t}+M_{r_{0}} \Phi=f_{0},\left.\Phi\right|_{t=0}=u_{0},\left.R \Phi\right|_{S}=g .
$$

In this case function $v=u-\Phi$ is a solution to equation

$$
L v_{t}+M v=\sum_{i=1}^{r_{0}} c_{i}(t) f_{i}(x, t)-\sum_{i=r_{0}+1}^{r} c_{i}(t) M_{i} \Phi=F(\vec{c}),
$$

satisfying homogeneous conditions (4). There exists $\gamma_{0}>0$ such that condition (12), with $\delta_{0} / 2$ rather than $\delta_{0}$, holds on $\left[0, \gamma_{0}\right]$. In this case

$$
v\left(t, x_{j}\right)=\alpha_{j}(t)-\Phi\left(t, x_{j}\right)=\tilde{\alpha}_{j}(t) .
$$

Function $\Phi \in W_{p}^{2}\left(G ; W_{p}^{1}(0, T)\right)$ after a possible modification on a set of zero measure possesses property $\Phi \in C^{\alpha}\left(\bar{G} ; W_{p}^{1}(0, T)\right)$ for $\alpha \leq 2-\frac{n}{p}$ (see (5.4) in [28]).

In particular, $\Phi\left(x_{i}, t\right) \in W_{p}^{1}(0, T)$, and thus

$$
\tilde{\alpha}_{j}(t) \in W_{p}^{1}(0, T) \quad(j=1,2, . ., r) .
$$


Inverting $L$ in (13), we have

$$
v_{t}+L^{-1} M v-v_{0}(v)=L^{-1} F(\vec{c}),
$$

where $v_{0}(v)=0$ in the case of the Dirichlet boundary conditions and is a solution to problem $L v_{0}=0,\left.R v_{0}\right|_{S}=-R_{t} v$ otherwise.

Note that $L^{-1} M_{i} \Phi\left(t, x_{j}\right)$ and $L^{-1} M_{i} \Phi\left(t, x_{j}\right) \in L_{\infty}(0, T)$ for almost all $t$. Actually, $L^{-1} M_{i} \Phi(x, t) \in W_{p}^{2}\left(G ; L_{p}(0, T)\right)$ and thereby $L^{-1} M_{i} \Phi\left(t, x_{j}\right) \in L_{p}(0, T)$ (see [28, (5.4)]). Let $x=x_{j}$ in (16). We have

$$
v_{t}\left(t, x_{j}\right)+L^{-1} M v\left(t, x_{j}\right)-v_{0}(v)\left(t, x_{j}\right)=L^{-1} F(\vec{c})\left(t, x_{j}\right) .
$$

The overdetermination conditions yield

$$
\begin{gathered}
\tilde{\alpha}_{j t}+R(v)\left(t, x_{j}\right)=L^{-1} F(\vec{c})\left(t, x_{j}\right), \\
R(v)=L^{-1} M_{r_{0}} v-v_{0}(v)+\sum_{i=r_{0}+1}^{r} c_{i}(t) L^{-1} M_{i} v .
\end{gathered}
$$

We can rewrite the last equations in form

$$
B \vec{c}=\left(\begin{array}{c}
\tilde{\alpha}_{1 t}+R(v)\left(t, x_{1}\right) \\
\cdots \\
\cdots \\
\left.\tilde{\alpha}_{r t}+R(v)\left(t, x_{r}\right)\right)
\end{array}\right) .
$$

As a result, we infer

$$
\vec{c}=B^{-1}\left(\begin{array}{c}
\tilde{\alpha}_{1 t}+R(v)\left(t, x_{1}\right) \\
\cdots \\
\cdots \\
\left.\tilde{\alpha}_{r t}+R(v)\left(t, x_{r}\right)\right)
\end{array}\right)=S(\vec{c}) .
$$

The right-hand side can be viewed as an operator $S(\vec{c})$ taking vector $\vec{c}(t)$ in solution $v(x, t)$ to equation (13) satisfying homogeneous conditions (4) and then taking $v(x, t)$ into the right-hand side of (18). System (18) is the desired system. The properties of this operator $S$ can be described as follows. Fix

$$
R_{0}=2\left\|B^{-1} \overrightarrow{\tilde{\alpha}}\right\|_{L_{p}(0, T)}, \quad \overrightarrow{\tilde{\alpha}}=\left(\tilde{\alpha}_{1 t}, \ldots, \tilde{\alpha}_{r t}\right)^{T},
$$

where norm $\left\|B^{-1} \overrightarrow{\tilde{\alpha}}\right\|_{L_{p}(0, T)}$ is just the sum of the norms of the coordinates of vector $B^{-1} \overrightarrow{\tilde{\alpha}}$ in space $L_{p}(0, T)$. We assume that

$$
\vec{c}(t) \in B_{R_{0}, \gamma}=\left\{\vec{c} \in L_{p}(0, \gamma):\|\vec{c}\|_{L_{p}(0, \gamma)} \leq R_{0}\right\}, \quad \gamma \leq T .
$$

We now can state that there exists constant $c>0$ and $\gamma_{0}>0$ such that operator $S$ : $B_{R_{0}, \gamma} \rightarrow B_{R_{0}, \gamma}, \gamma \leq \gamma_{0}$ takes ball $B_{R_{0}, \gamma}$ into itself and is a contraction. More exactly, we have the estimate

$$
\left\|S\left(\overrightarrow{c^{1}}\right)-S\left(\vec{c}^{2}\right)\right\|_{L_{p}\left(0, \gamma_{0}\right)} \leq c \gamma^{1 / q}\left\|\vec{c}^{1}-\vec{c}^{2}\right\|_{L_{p}\left(0 \gamma_{0}\right)} \forall \vec{c}^{1}, \vec{c}^{2} \in B_{R_{0}, \gamma}
$$

and thus this operator is a contraction for all $\gamma \leq \gamma_{0}$ with $c \gamma_{0}^{1 / q}=1 / 2$. The method of successive approximations $\vec{c}^{n}=S\left(\vec{c}^{n-1}\right)(n=1,2, \ldots), \vec{c}^{0}=0$ converges to a solution to equation (18). The proof of these facts is in line with that in [14]. So we omit it. 


\section{Description of the Algorithm}

To simplify the presentation, we describe the idea of the algorithm in the model case which in particular includes the filtration problems described in the introduction. We rely on some integral identities. Consider problem

$$
\begin{gathered}
L_{0} u_{t}+k(t) L_{1} u=f, \\
\left.\frac{\partial u}{\partial n}\right|_{\Gamma}=g, \quad u(0)=u_{0}(x), \\
u\left(x_{0}, t\right)=\psi_{0}(t),
\end{gathered}
$$

where

$$
\begin{gathered}
L_{0} u=-\operatorname{div}\left(a_{0}(x, t) \nabla u_{t}\right)+b_{0}(x, t) \cdot \nabla u+c_{0}(x, t) u, \\
L_{1} u=-\operatorname{div}\left(a_{1}(x, t) \nabla u\right)+b_{1}(x, t) \cdot \nabla u+c_{1}(x, t) u
\end{gathered}
$$

and $a_{0}, a_{1}, c_{0}, c_{1}$ are scalar functions and $b_{0}, b_{1}$ are vector-function of length $n$. Functions $u$ and $k(t)$ are unknown. We assume that all conditions of Theorem 1 for the data are fulfilled. Function $\Phi$ is a solution to problem (19), (20). Since the existence theorem is local in time, we can replace condition (12) with the following condition: there exists $t_{0}>0$ such that

$$
\left|L_{0}^{-1} L_{1} \Phi\left(x_{0}, t\right)\right| \geq \delta_{0}>0 \forall t \in\left[0, t_{0}\right]
$$

or in a simpler form

$$
\left|L_{0}^{-1} L_{1} u_{0}\left(x_{0}\right)\right| \geq \delta_{0}>0 \forall t \in\left[0, t_{0}\right] .
$$

Let $\varphi \in L_{q}\left(0, T ; W_{q}^{1}(G)\right)(1 / q+1 / p=1)$ be a test function and let a function $u$ be a solution to problem (19), (20) from the class pointed out in Theorem 1. Integrating by parts in identity

$$
\left(L_{0} u_{t}, \varphi\right)+k(t)\left(L_{1} u, \varphi\right)=(f, \varphi), \varphi \in L_{q}\left(0, T ; W_{q}^{1}(G)\right)
$$

we arrive at equality

$$
a\left(u_{t}, \varphi\right)+k(t) b(u, \varphi)=l(\varphi)+k(t) l_{1}(\varphi)
$$

where $a\left(u_{t}, \varphi\right)=\left(a_{0} \nabla u_{t}, \nabla \varphi\right)+\left(b_{0} \cdot \nabla u_{t}+c_{0} u_{t}, \varphi\right), b(u, \varphi)=\left(a_{1} \nabla u, \nabla \varphi\right)+\left(b_{1} \cdot \nabla u+c_{1} u, \varphi\right)$, $l(\varphi)=(f, \varphi)+l_{0}(\varphi), l_{0}(\varphi)=\int_{\Gamma} a_{0} g_{t} \varphi d \Gamma, l_{1}(\varphi)=\int_{\Gamma} a_{1} g \varphi d t$.

Next, we look for solution $\varphi_{0}(x, t)$ to problem

$$
L_{0}^{*} \varphi_{0}=\delta\left(x-x_{0}\right), \quad a_{0} \frac{\partial \varphi_{0}}{\partial n}+\left.b \cdot n \varphi_{0}\right|_{\Gamma}=0,
$$

where $L_{0}^{*}$ is a formally adjoint to $L_{0}$ and $\delta$ is the Dirac delta-function. Inserting $\varphi_{0}$ in (24), we obtain that

$$
\psi_{t}+k(t)\left(b\left(u, \varphi_{0}\right)-l_{1}(\varphi)\right)=l\left(\varphi_{0}\right)
$$

Hence, we conclude that

$$
k(t)\left(b\left(u, \varphi_{0}\right)-l_{1}\left(\varphi_{0}\right)\right)=l\left(\varphi_{0}\right)-\psi_{t} .
$$


Note that definition of $\varphi_{0}$ implies that $b\left(u, \varphi_{0}\right)-l_{1}\left(\varphi_{0}\right)=L_{0}^{-1} L_{1} u\left(x_{0}, t\right)$. Since $\left|L_{0}^{-1} L_{1} u_{0}\left(x_{0}\right)\right|>\delta_{0}>0$ on some segment $\left[0, t_{0}\right]$ we can say that $\left|\left(b\left(u_{0}, \varphi_{0}\right)-l_{1}\left(\varphi_{0}\right)\right)\right|>0$ on some segment of time. Integral identities (27) allows us to construct the iteration procedure realized in the proof of Theorem 1 . To avoid an excessive calculations, we can omit the determination of $\Phi$ in our case. Let $k^{0}=\left(l_{0}\left(\varphi_{0}\right)-\psi_{t}\right) /\left.\left(b\left(u_{0}, \varphi_{0}\right)-l_{1}\left(\varphi_{0}\right)\right)\right|_{t=0}$. Given function $k^{i}$, we can construct $u^{i+1}$ as a solution to problem (19), (20) with $k(t)=k^{i}(t)$ and to determine next iteration $k^{i+1}$ from one of the equalities

$$
\begin{gathered}
k^{i+1}(t)=\left(l\left(\varphi_{0}\right)-\psi_{t}\right) /\left(b\left(u^{i+1}, \varphi_{0}\right)-l_{1}\left(\varphi_{0}\right)\right), \\
k^{i+1}=\left(l\left(\varphi_{0}\right)-\psi_{t}-k^{i} b\left(u^{i+1}-u_{0}, \varphi_{0}\right)\right) /\left(b\left(u_{0}, \varphi_{0}\right)-l_{1}\left(\varphi_{0}\right)\right) .
\end{gathered}
$$

The latter formula almost corresponds to the iteration procedure in the proof of the fixed point theorem for operator $S$ constructed in Theorem 1 . The peculiarity is that we have replaced function $\Phi$ with function $u_{0}$. It can be easily clarified that all arguments remain valid in this case. Denominator in $(29)$ is different from zero on some segment $\left[0, t_{0}\right]$. Former formula (28) corresponds an another operator $S$ but the same arguments can be used to prove that the iteration procedure corresponding to formula (28) converges as well on some small time segment $\left[0, t_{0}\right]$.

\section{Numerical Algorithm}

The algorithm is iterative and relies on the finite element method. We define triangulation of $G$, mesh nodes, $x_{1}, x_{2}, \ldots, x_{N}$, and corresponding piecewise linear functions $\left\{\varphi_{i}(x)\right\}$ (thus, $\varphi_{i}\left(x_{j}\right)=\delta_{i j}$, where $\delta_{i j}$ is the Kronecker symbol. Without loss of generality, we can assume that observation point $x_{0}$ is mesh node $x_{j_{0}}$. Approximate solution to (19), (20) is sought in form $u^{m+1}=\sum_{i=1}^{N} c_{i}(t) \varphi_{i}(x)$. To determine the functions $c_{i}$ we employ integral identity (24). Vector-function $C(t)=\left(c_{1}(t), c_{2}(t), \ldots, c_{N}(t)\right)^{T}$ is a solution to system of ordinary differential equations

$$
A C_{t}+k(t) B C=F, C(0)=\left(u_{0}\left(x_{1}\right), u_{0}\left(x_{2}\right), \ldots, u_{0}\left(x_{N}\right)\right)^{T},
$$

where $A, B$ are matrices with entries $a_{i j}=a\left(\varphi_{j}, \varphi_{i}\right), b_{i j}=b\left(\varphi_{j}, \varphi_{i}\right)$, and $F=$ $\left(F_{1}, \ldots, F_{N}\right)^{T}, F_{i}(t)=l_{0}\left(\varphi_{i}\right)+k(t) l_{1}\left(\varphi_{i}\right)$. To solve $(30)$, we involve the finite difference method (FDM) (the implicit scheme) and replace (30) with finite difference equation

$$
A_{n} \frac{C_{n}-C_{n-1}}{\tau}+k_{n} B_{n} C_{n}=F_{0, n}+k_{n} F_{1, n}, C_{0}=C(0),
$$

where $n=1,2, \ldots, M, \tau=T / M$, and $F_{0 n}, F_{1 n}, A_{n}, B_{n}$ are the values of the right-hand side in (30), and matrices $A, B$ at $n \tau$. We assume here that approximation $\tilde{k}$ of $k$ is a piecewise constant function taking value $k_{n}$ on $((n-1) \tau, n \tau]$. Respectively, a piecewise constant approximation of solution $C(t)$ to (30) is a piecewise constant function equal to vector $C_{n}$ on set $((n-1) \tau, n \tau]$. An analog of the overdetermination condition is as follows:

$$
\frac{C_{n}-C_{n-1}}{\tau}=\psi_{0 t}((n-1) \tau) .
$$

Since our results are local in time, we employ the predictor-corrector arguments. Given vector $C$, denote its $j$-th coordinate by $(C)_{j}$. Find quantity $k_{0}=\left(\left(A_{0}^{-1} F_{0,0}\right)_{j_{0}}-\right.$ 
$\left.\psi_{t}(0)\right) /\left(\left(A_{0}^{-1} B_{0} C_{0}\right)_{j_{0}}-\left(A_{0}^{-1} F_{1,0}\right)_{j_{0}}\right)$. Put $k_{1}^{1}=k_{0}$. Let the approximation $k_{1}^{i}$ of quantity $k_{1}$ be known. Find solution $C_{1}^{i}$ to equation (31) with $n=1$ and $k_{1}=k_{1}^{i}$, i.e.

$$
A_{1} \frac{C_{1}^{i}-C_{0}}{\tau}+k_{1}^{i} B_{n} C_{1}^{i}=F_{0,1}+k_{1}^{i} F_{1,1} .
$$

The next approximation is defined as

$$
k_{1}^{i+1}=\left(\left(A_{1}^{-1} F_{0,1}\right)_{j_{0}}-\psi_{t}(0)\right) /\left(\left(A_{1}^{-1} B_{1} C_{1}^{i}\right)_{j_{0}}-\left(A_{1}^{-1} F_{1,1}\right)_{j_{0}}\right) .
$$

We repeat the arguments until $\left|k_{1}^{i+1}-k_{1}^{i}\right|<\varepsilon$ with $\varepsilon$ a prescribed small number. Next we take $k_{1}:=k_{1}^{i+1}$. We have find quantity $k_{1}$ and corresponding vector $C_{1}:=C_{1}^{i+1}$. Assume that we have found $k_{1}, \ldots, k_{m}(m<M)$ and vectors $C_{1}, \ldots, C_{m}$. Take $k_{m+1}^{1}:=k_{m}$ and calculate quantities $k_{m+1}^{i}$ for all $i$ as follows. Assume that quantity $k_{m+1}^{i}$ is known. Find solution $C_{m+1}^{i}$ to equation (31) with $n=m+1$ and $k_{n}=k_{m+1}^{i}$, i.e.

$$
A_{m+1} \frac{C_{m+1}^{i}-C_{m}}{\tau}+k_{m+1}^{i} B_{m+1} C_{m+1}^{i}=F_{0, m+1}+k_{m+1}^{i} F_{1, m+1} .
$$

Next, we calculate

$$
k_{m+1}^{i+1}=\left(\left(A_{m+1}^{-1} F_{0, m+1}\right)_{j_{0}}-\psi_{t}(m \tau)\right) / l_{m+1}^{i},
$$

where $l_{m+1}^{i}=\left(\left(A_{m+1}^{-1} B_{m+1} C_{m+1}^{i}\right)_{j_{0}}-\left(A_{m+1}^{-1} F_{1, m+1}\right)_{j_{0}}\right)$. We repeat the arguments until $\left|k_{m+1}^{i+1}-k_{m+1}^{i}\right|<\varepsilon$. In this case we put $k_{m+1}:=k_{m+1}^{i+1}$ and $C_{m+1}:=C_{m+1}^{i+1}$. The arguments are repeated until $m=M$. It is possible of course that the process stops at some iteration (for instance, if the denominator in (36) becomes equal to zero). It is possible due to the nonlinearity of the problem. Formula (36) corresponds to equality (28).

\section{The Results of Numerical Experiments}

In this section we analyze the results of numerical experiments. The characteristics of the computer are as follows: processor Intel(R) Core(TM) i7-3517U CPU @ $1.90 \mathrm{GHz}$ 2.40GHz, 10.00 GB RAM, 64-digit operating system Windows 7 Enterprise.

As a result of calculations, we obtain approximate values of solution $(u(x, y, t), k(t))$ of problem $(19)-(20)$ at points $\left(t_{1}, t_{2}, \ldots t_{N}\right)$. Here point $(x, y)$ belongs to the unit circle centered at $(0,0)$. We present the results of calculations only for function $k$.

To solve the problem numerically, we use three meshes for this domain with the number of nodes $N_{1}=197, N_{2}=751$ and $N_{3}=2933$ (Fig. 1). Additional information (21) is given at observation point $x_{j_{0}}=\left(x_{0}, y_{0}\right)=(0,3,-0,3)$.

All numerical experiments are divided into two groups in dependence on unknown functions $u, k$, the boundary conditions, noise percentage $\delta$, error between iterations $\varepsilon$, coefficients $a_{0}, a_{1}, b_{0,1}, b_{0,2}, b_{1,1}, b_{1,2}, c_{0}, c_{1}$, and right-hand sides $f$.

We will use the Neumann boundary conditions from (24) which are represented as

$$
\left.\frac{\partial u}{\partial n}\right|_{\Gamma}=\left(u_{x} x+u_{y} y\right)=g
$$

The data of the first group are as follows:

- solution: $u(x, y, t)=\left(x^{2}+y^{2}+1\right) \cdot(1+t)$;

- initial data: $\left.u\right|_{t=0}=x^{2}+y^{2}+1$; 


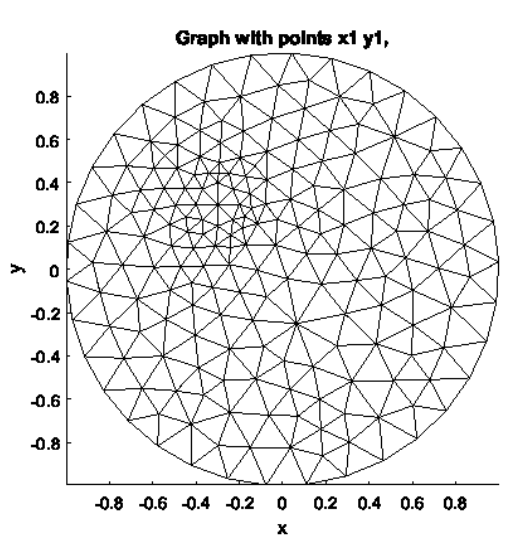

a)

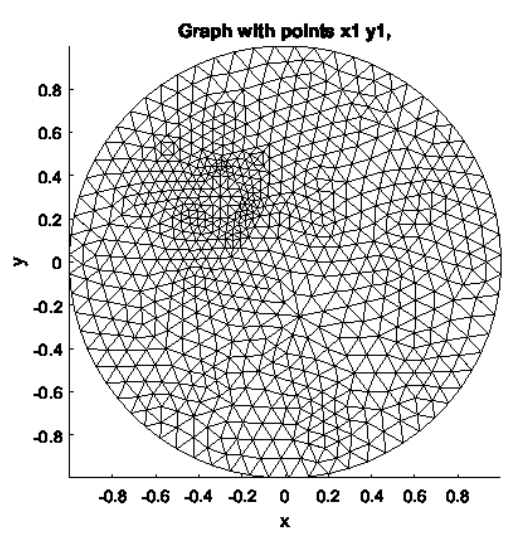

b)

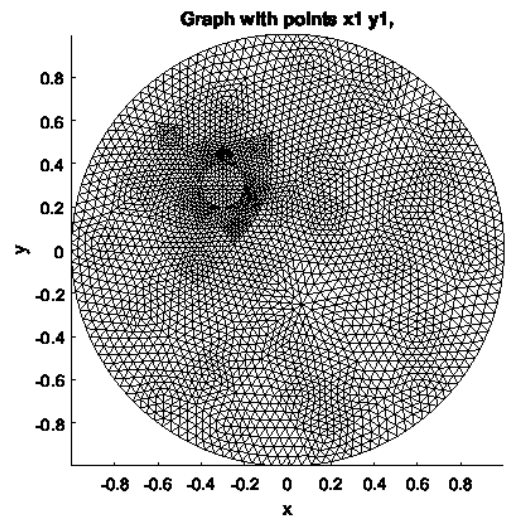

c)

Fig. 1. Meshes: a) $N_{1}=197$; b) $N_{2}=751$; c) $N_{3}=2933$

- Neumann boundary conditions: $g=2\left(x^{2}+y^{2}\right)(1+t)$;

- additional information: $\psi\left(x_{j_{0}}, t\right)=\left(x_{0}^{2}+y_{0}^{2}+1\right) \cdot(1+t)$;

- unknown function: $k(t)=t^{2}$

- coefficients: $a_{0}=0,5, a_{1}=4 /(1+t), b_{0,1}=b_{0,2}=b_{1,1}=b_{1,2}=0, c_{0}=1 /\left(x_{1}^{2}+x_{2}^{2}+1\right)$, $c_{1}=1 /(1+t)$

- right-hand side: $f=t^{2} \cdot\left(x^{2}+y^{2}-15\right)-1$.

We compare the results of calculations for three meshes for the data without noise, i.e. $\delta=0$. Take $\varepsilon=10^{-3}$ (the error defined by the user). Denote by $\tau$ the time of the work of the algorithm in seconds. Introduce one more error of the algorithm by equality $\varepsilon_{0}=\max _{m}\left|k_{m}-k(m \Delta t)\right|$, where $m=1,2, \ldots, N$. Consider segment $[0, T], T=1$, and take $\Delta t=T / N, N=100$.

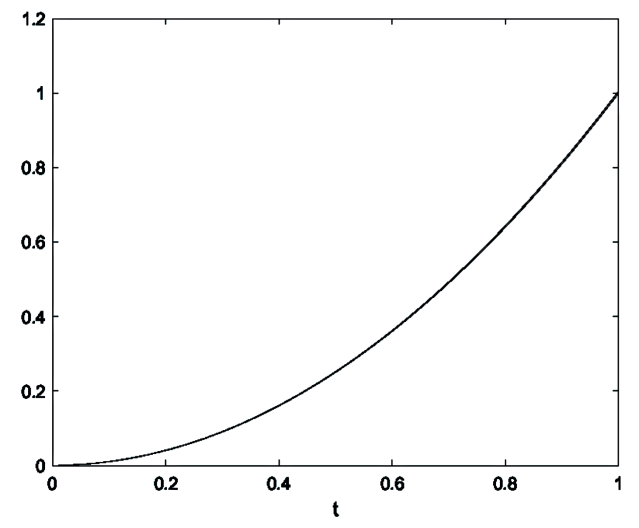

Fig. 2. Results of calculations for the meshes: $N_{1}: \tau=9,81, \varepsilon_{0}=0,0058 ; N_{2}: \tau=131,62$, $\varepsilon_{0}=0,0015 ; N_{3}: \tau=3820,1, \varepsilon_{0}=0,00035$

The obtained plots of original functions $k(t)$ and their approximation for three different meshes are almost identical, so we present only one of them for the first mesh. For the following experiments, add 10, 20 and 40 percent random noise to the overdetermination data: $\tilde{\psi}_{t}\left(x_{0}, t\right)=\psi_{t}\left(x_{0}, t\right)(1+\delta(2 \sigma-1))$, where $\sigma$ is random function normally distributed on interval $[0,1]$. Due to the almost complete coincidence of the graphs of the original and the approximated function, we give only the graphics with noise 40 percent and $\varepsilon=10^{-3}$. 


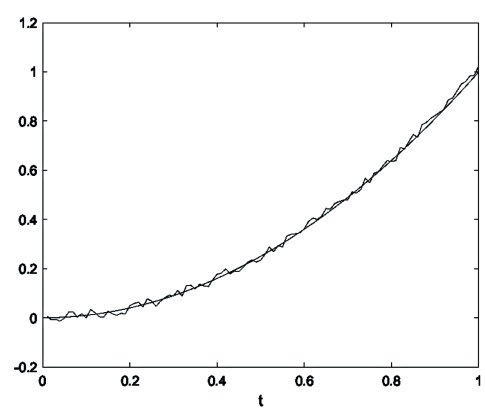

a)

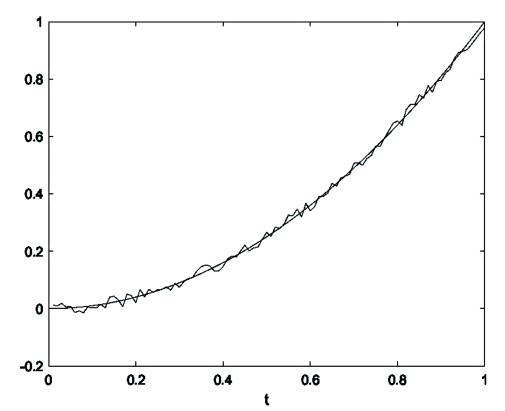

b)

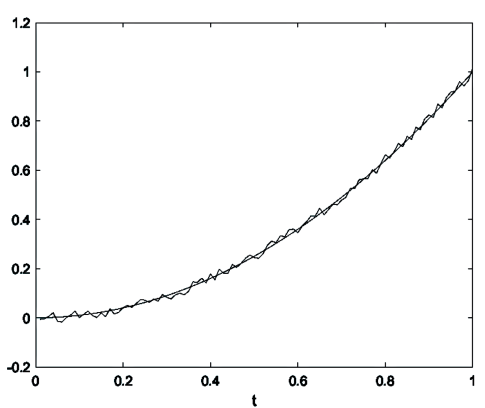

c)

Fig. 3. Results of calculations for the meshes: a) $N_{1}: \tau=8,41, \varepsilon_{0}=0,0286$; b) $N_{2}$ : $\tau=110,5, \varepsilon_{0}=0,0231$; c) $N_{3}: \tau=3983,1, \varepsilon_{0}=0,0232$

Fig. 3 shows that, the obtained plots of original functions $k(t)$ and their approximation are almost identical and regardless of the level of input noise $\delta$, the results of the calculations repeat the ones sought or are located next to them. Table 1 shows the results for different input data.

Table 1

Results of numerical experiments (first group)

\begin{tabular}{|c|c|c|c|c|}
\hline No exp. & Grid & $\delta$ & $\varepsilon_{0}$ & $\tau$ \\
\hline 1 & $N_{1}$ & 0 & 0,0058 & 8,41 \\
\hline 2 & $N_{1}$ & 0,1 & 0,0106 & 8,8 \\
\hline 3 & $N_{1}$ & 0,2 & 0,0166 & 8,51 \\
\hline 4 & $N_{1}$ & 0,3 & 0,0187 & 8,3 \\
\hline 5 & $N_{2}$ & 0 & 0,0015 & 110,5 \\
\hline 6 & $N_{2}$ & 0,1 & 0,0066 & 109,4 \\
\hline 7 & $N_{2}$ & 0,2 & 0,0114 & 114,32 \\
\hline 8 & $N_{2}$ & 0,3 & 0,018 & 118,57 \\
\hline 9 & $N_{3}$ & 0 & 0,00035 & 3983,1 \\
\hline 10 & $N_{3}$ & 0,1 & 0,0058 & 3773,3 \\
\hline 11 & $N_{3}$ & 0,2 & 0,0117 & 3730,4 \\
\hline 12 & $N_{3}$ & 0,3 & 0,0174 & 3821,9 \\
\hline
\end{tabular}

Based on the results of numerical experiments for the first group of data, we can conclude that the increase in the number of nodes in 4 times leads to the increase in the calculation time by an average of $\approx 12$ times for grids $N_{1}$ and $N_{2}$ and $\approx 42$ times for grids $N_{2}$ and $N_{3}$, but does not lead to a significant increase in accuracy and with the increase in the noise level.

Let us describe the data of the second group:

- solution: $u(x, y, t)=\left(x^{2}+1\right) \cdot\left(y^{2}+1\right) \cdot(1+t)$;

- initial data: $\left.u\right|_{t=0}=\left(x^{2}+1\right) \cdot\left(y^{2}+1\right)$;

- Neumann boundary conditions: $g=2(t+1)\left(y\left(x^{2}+1\right)+x\left(y^{2}+1\right)\right)$;

- additional information: $\psi\left(x_{j_{0}}, t\right)=\left(x_{0}^{2}+1\right) \cdot\left(y_{0}^{2}+1\right) \cdot(1+t)$;

- unknown function: $k(t)=(t-0,5)^{3}$;

- coefficients: $a_{0}=(t+1)\left(x^{2}+1\right), a_{1}=\left(t^{2}+y+4\right) /\left(x^{2}+1\right), b_{0,1}=x^{3} * t, b_{0,2}=(x+y) * t$, $b_{1,1}=y^{2} /(t+1), b_{1,2}=x t /(y+1), c_{0}=t y /\left(x^{2}+1\right), c_{1}=(x+t) /(2+y)$; 
- right-hand side: $f=\left(2\left(x^{2}+1\right)^{2}\right) /(t+1)+(t-0.5)^{3}\left(\left(\left(x^{2}+1\right)\left(y^{2}+1\right)\right) /(t+1)^{2}-\right.$ $\left(2 y+2 t^{2}+8\right) /(t+1)-(2 y) /(t+1)-\left(2\left(y^{2}+1\right)\left(y+t^{2}+4\right)\right) /\left(\left(x^{2}+1\right)(t+1)\right)+\left(2 x y^{2}\left(y^{2}+\right.\right.$ $1)) /(t+1)^{2}+\left(4 x^{2}\left(y^{2}+1\right)\left(y+t^{2}+4\right)\right) /\left(\left(x^{2}+1\right)^{2}(t+1)\right)+\left(2 t x y\left(x^{2}+1\right)\right) /((t+1)(y+$ $1)))+\left(2\left(x^{2}+1\right)\left(y^{2}+1\right)\right) /(t+1)+\left(4 x^{2}\left(y^{2}+1\right)\right) /(t+1)-\left(2 t x^{4}\left(y^{2}+1\right)\right) /(t+1)^{2}-\left(\left(x^{2}+\right.\right.$ $\left.1)\left(y^{2}+1\right)\right) /\left((t+1)^{2}\left(x^{2}+y^{2}+1\right)\right)-\left(2 t y\left(x^{2}+1\right)(x+y)\right) /(t+1)^{2}$.

Since the results for different grids are similar, we present them for the grid $N_{1}$. As in the case of the first group, we vary parameters $\varepsilon$ and $\delta$.

Table 2

Results of numerical experiments for the second group of data

\begin{tabular}{|c|c|c|c|c|c|}
\hline No exp. & Grid & $\delta$ & $\varepsilon$ & $\varepsilon_{0}$ & $\tau$ \\
\hline 1 & $N_{1}$ & 0 & $10^{-4}$ & 0,0035 & 7,1 \\
\hline 2 & $N_{1}$ & 0 & $10^{-5}$ & 0,0035 & 6,35 \\
\hline 3 & $N_{1}$ & 0 & $10^{-6}$ & 0,0035 & 6,59 \\
\hline 4 & $N_{1}$ & 0 & $10^{-7}$ & 0,0035 & 7,02 \\
\hline 5 & $N_{1}$ & 0,2 & $10^{-4}$ & 0,0156 & 6,2 \\
\hline 6 & $N_{1}$ & 0,2 & $10^{-5}$ & 0,0126 & 5,85 \\
\hline 7 & $N_{1}$ & 0,2 & $10^{-6}$ & 0,0151 & 6 \\
\hline 8 & $N_{1}$ & 0,2 & $10^{-7}$ & 0,0137 & 6,6 \\
\hline 9 & $N_{1}$ & 0,4 & $10^{-4}$ & 0,0291 & 6,38 \\
\hline 10 & $N_{1}$ & 0,4 & $10^{-5}$ & 0,0246 & 6,94 \\
\hline 11 & $N_{1}$ & 0,4 & $10^{-6}$ & 0,0262 & 8,08 \\
\hline 12 & $N_{1}$ & 0,4 & $10^{-7}$ & 0,0273 & 8,2 \\
\hline
\end{tabular}

As we can see the decrease in variable $\varepsilon$ does not lead to a significant increase in the accuracy and decreasing the time of calculations. In the next two experiments we reduce the time step in 5 times.

Table 3

Results of numerical experiments for the second group of data, time step 0,002

\begin{tabular}{|c|c|c|c|c|c|}
\hline No exp. & Grid & $\delta$ & $\varepsilon$ & $\varepsilon_{0}$ & $\tau$ \\
\hline 1 & $N_{1}$ & 0 & $10^{-4}$ & 0,0031 & 36,41 \\
\hline 2 & $N_{1}$ & 0 & $10^{-5}$ & 0,0031 & 32,69 \\
\hline 3 & $N_{1}$ & 0 & $10^{-6}$ & 0,0031 & 32,41 \\
\hline 4 & $N_{1}$ & 0 & $10^{-7}$ & 0,0031 & 35,56 \\
\hline 5 & $N_{1}$ & 0,2 & $10^{-4}$ & 0,0147 & 47,44 \\
\hline 6 & $N_{1}$ & 0,2 & $10^{-5}$ & 0,0146 & 37,77 \\
\hline 7 & $N_{1}$ & 0,2 & $10^{-6}$ & 0,0142 & 36,28 \\
\hline 8 & $N_{1}$ & 0,2 & $10^{-7}$ & 0,0153 & 42,46 \\
\hline 9 & $N_{1}$ & 0,4 & $10^{-4}$ & 0,0263 & 45,27 \\
\hline 10 & $N_{1}$ & 0,4 & $10^{-5}$ & 0,0269 & 56,34 \\
\hline 11 & $N_{1}$ & 0,4 & $10^{-6}$ & 0,0273 & 56,35 \\
\hline 12 & $N_{1}$ & 0,4 & $10^{-7}$ & 0,0272 & 54,81 \\
\hline
\end{tabular}

Summing up, we can say that the use of a grid with a large number of nodes shows better accuracy, but the time of the calculation increases by an amount equal to the ratio 
of the number of nodes of the three grids. Decreasing the variable $\varepsilon$ leads to an increase in the computation time $\tau$, but does not lead to a significant increase in accuracy. We also see that the dependence of the time of a calculation on the time step is inversely proportional.

\section{Conclusions}

We establish the existence and uniqueness theorems in inverse problems of recovering the coefficients of a pseudoparabolic equation with pointwise overdetermination conditions. Actually, we have proven that the problems in questions are well-posed in the usual sense at least locally in time. The problem is reduced to an operator equation of Volterra type. This allows to construct a numerical algorithms based on the conventional methods (in our case FEM and difference schemes) with a sufficiently good convergence to a solution. The results of numerical experiments are presented.

Acknowledgements. This work was supported by the science foundation of Yugra State University (Grant no. 13-01-20/16) and by the Act 211 of the Government of the Russian Federation, contract no. 02.A03.21.0011.

\section{References}

1. Barenblatt G.I., Zheltov Iu.P., Kochina I.N. Basic Concepts in the Theory of Seepage of Homogeneous Liquids in Fissured Rocks. Journal of Applied Mathematics and Mechanics, 1960, vol. 24, no. 5, pp. 1286-1303. DOI: 10.1016/0021-8928(60)90107-6

2. Böhm M., Showalter R.E. Diffusion in Fissured Media. SIAM Journal on Mathematical Analysis, 1985, vol. 16, no. 3, pp. 500-509. DOI: 10.1137/0516036

3. Lyubanova A.Sh., Tani A. On Inverse Problems for Pseudoparabolic and Parabolic Equations of Filtration. Inverse Problems in Science and Engineering, 2011, vol. 19, no. 7, pp. 1023-1042. DOI: $10.1080 / 17415977.2011 .569712$

4. Al'shin A.B., Korpusov M.O., Sveshnikov A.G. Blow-up in Nonlinear Sobolev Type Equations. Berlin, N.Y., De Gruyter, 2011. DOI: 10.1515/9783110255294

5. Sviridyuk G.A., Fedorov V.E. Linear Sobolev Type Equations and Degenerate Semigroups of Operators. Utrecht, VSP, 2003. DOI: 10.1515/9783110915501

6. Favini A., Yagi A. Degenerate Differential Equations in Banach Spaces. N.Y., Marcel Dekker, 1999.

7. Rundell W. Determination of an Unknown Nonhomogeneous Term in a Linear Partial Differential Equation from Overspecified Boundary Data. Journal of Applied Analysis, 1980, vol. 10, no. 3, pp. 231-242. DOI: 10.1080/00036818008839304

8. Kozhanov A.I. Composite Type Equations and Inverse Problems. Utrecht, VSP, 1999. DOI: $10.1515 / 9783110943276$

9. Asanov A., Atamanov E.R. Nonclassical and Inverse Problems for Pseudoparabolic Equations. Berlin, De Gruyter, 2014.

10. Favini A., Lorenzi A. Differential Equations. Inverse an Direct Problems. Abingdon, Tylor and Francis Group, 2006. DOI: 10.1201/9781420011135

11. Mamayusupov M.Sh. The Problem of Determining Coefficients of a Pseudoparabolic Equation. Studies in Integro-Differential Equations, 1983, vol. 16, pp. 290-297.

12. Lyubanova A.Sh. Identification of a Coefficient in the Leading Term of a Pseudoparabolic Equation of Filtration. Siberian Mathematical Journal, 2013, vol. 54, no. 6, pp. 1046-1058. DOI: $10.1134 /$ S0037446613060116 
13. Lyubanova A.Sh. The Inverse Problem for the Nonlinear Pseudoparabolic Equation of Filtration Type. Journal of Siberian Federal University. Series: Mathematics and Physics, 2017, vol. 10, no. 1, pp. 4-15.

14. Pyatkov S.G., Shergin S.N. On Some Mathematical Models of Filtration Theory. Bulletin of the South Ural State University. Series: Mathematical Modelling, Programming and Computer Software, 2015, vol. 8, no. 2, pp. 105-116.

15. Kabanikhin S.I. Inverse and Ill-Posed Problems. Berlin, Boston, De Gruyter, 2012.

16. Samarskii A.A., Vabishchevich P.N. Numerical Methods for Solving Inverse Problems of Mathematical Physics. Berlin, Boston, De Gruyter, 2007. DOI: 10.1515/9783110205794

17. Ewing R.E. Numerical Solution of Sobolev Partial Differential Equations. SIAM Journal on Numerical Analysis, 1975, vol. 12, no. 3, pp. 345-363. DOI: 10.1137/0712028

18. Cuesta C.M., Pop I.S. Numerical Schemes for a Pseudo-Parabolic Burgers Equation, Discontinuous Data and Long-Time Behaviour. Journal of Computational and Applied Mathematics, 2009, vol. 224, no. 1, pp. 269-283. DOI: 10.1016/j.cam.2008.05.001

19. Beshtokov M.Kh. Differential and Difference Boundary Value Problem for Loaded ThirdOrder Pseudo-Parabolic Differential Equations and Difference Methods for Their Numerical Solution. Computational Mathematics and Mathematical Physics, 2017, vol. 57, no. 12, pp. 1973-1993. DOI: 10.1134/S0965542517120089

20. Vabishchevich P.N., Grigor'ev A.V. Splitting Schemes for Pseudoparabolic Equations. Differential Equations, 2013, vol. 49, no. 7, pp. 807-814. DOI: 10.1134/S0012266113070033

21. Guezane-Lakoud A., Belakroum D. Time-Discretization Schema for an Integrodifferential Sobolev Type Equation with Integral Conditions. Applied Mathematics and Computation, 2012, vol. 218, no. 9, pp. 4695-4702. DOI: 10.1016/j.amc.2011.11.077

22. Luoa Z.D. Teng F. A Reduced-Order Extrapolated Finite Difference Iterative Scheme Based on POD Method for 2D Sobolev Equation. Applied Mathematics and Computation, 2018, vol. 329, pp. 374-383. DOI: 10.1016/j.amc.2018.02.022

23. Xia H., Luo Z. An Optimized Finite Difference Crank-Nicolson Iterative Scheme for the 2D Sobolev Equation. Advances in Difference Equations, 2017, vol. 196, 12 p. DOI: $10.1186 / \mathrm{s} 13662-017-1253-8$.

24. Keller A.V., Zagrebina S.A. Some Generalizations of the Schowalter-Sidorov Problem for Sobolev-Type Models. Bulletin of the South Ural State University. Series: Mathematical Modelling, Programming and Computer Software, 2015, vol. 8, no. 2, pp. 5-23.

25. Hasan A., Aamo A.M., Foss B. Boundary Control for a Class of Pseudo-Parabolic Differential Equations. Systems and Control Letters, 2013, vol. 62, no. 1, pp. 63-69. DOI: $10.1016 /$ j.sysconle.2012.10.009

26. Triebel H. Interpolation Theory, Function Spaces, Differential Operators. North-Holland Mathematical Library. Amsterdam, North-Holland Publishing, 1978.

27. Ladyzhenskaya O.A., Solonnikov V.A., Ural'tseva N.N. Linear and Quasi-Linear Equations of Parabolic Type. Providence, American Mathematical Society, 1968. DOI: $10.1090 / \mathrm{mmono} / 023$

28. Amann H. Operator-Valued Fourier Multipliers, Vector-Valued Besov Spaces and Applications. Mathematische Nachrichten, 1997, vol. 186, no. 1, pp. 5-56. DOI: $10.1002 /$ mana.3211860102

Received December 7, 2018 


\title{
О НЕКОТОРЫХ КОЭФФИЦИЕНТНЫХ ОБРАТНЫХ ЗАДАЧАХ С ТОЧЕЧНЫМ ПЕРЕОПРЕДЕЛЕНИЕМ ДЛЯ МАТЕМАТИЧЕСКИХ МОДЕЛЕЙ ФИЛЬТРАЦИИ
}

\author{
С.Н. Шергин ${ }^{1}$, Е.И. Сафонов ${ }^{1}$, С.Г. Пятков ${ }^{1,2}$, \\ ${ }^{1}$ Югорский государственный университет, г. Ханты-Мансийск, \\ Российская Федерация \\ ${ }^{2}$ Южно-Уральский государственный университет, г. Челябинск, \\ Российская Федерация
}

\begin{abstract}
Рассматриваются обратные задачи восстановления коэффициентов линейного псевдопараболического уравнения, возникающие в теории фильтрации. Граничные условия типа Неймана дополняются условиями переопределения, которые есть значения решения в некотором наборе внутренних точек области. Мы приводим теоремы существования и единственности решений в пространствах Соболева. Полученное решение является регулярным, то есть обладает всеми обобщенными производными, входящими в уравнение, принадлежащими некоторому пространству Лебега. Метод доказательства является конструктивным. Задача сводится к нелинейному операторному уравнению с сжимающим оператором, если временной промежуток достаточно мал. Используя метод доказательства, мы строим численный алгоритм определения решения, соответствующий программный комплекс и описываем результаты численных экспериментов в двухмерном случае по пространственным переменным. Определению подлежат само решение уравнения и коэффициент пьезопроводимости трещиноватой среды. Основной метод для численного определения решения - метод конечных элементов, который дополняется разностной схемой для решения соответствующей системы обыкновенных дифференциальных уравнений. В конечном счете задача сводится к решению нелинейной алгебраической системы, решение которой находится при помощи итерационной процедуры. Результаты показывают очень хорошую сходимость численного алгоритма.
\end{abstract}

Ключевые слова: обратная задача; псевдопараболическое уравнение; бильтрачия; численное решение.

Сергей Николаевич Шергин, аспирант, ведущий программист, отдел по набору и профориентационной работе, Югорский государственный университет (г. ХантыМансийск, Российская Федерация), ssn@ugrasu.ru.

Егор Иванович Сафонов, кандидат физико-математических наук, доцент, Высшая цифровая школа, Югорский государственный университет (г. Ханты-Мансийск, Российская Федерация), dc.gerz.hd@gmail.com.

Сергей Григорьевич Пятков, доктор физико-математических наук, профессор, заведующий кафедрой «Высшая математика», Югорский государственный университет (г. Ханты-Мансийск, Российская Федерация); научноисследовательская лаборатория «Неклассические уравнений математической физики», Южно-Уральский государственный университет (г. Челябинск, Российская Федерация), S_pyatkov@ugrasu.ru

Поступила в редакиию 7 декабря 2018 г.

Вестник ЮУрГУ. Серия «Математическое моделирование

и программирование» (Вестник ЮУрГУ ММП). 2019. Т. 12, № 1. С. 82-95 